\title{
Bazı Kiraz Çeşitlerinde Uygulanan Ön İşlemlerin Depolama Süresince Epikateşin ve Klorojenik Asit Miktarına Etkileri
}

\author{
Zekiye GÖKSEL ${ }^{1, *}$, Uygun AKSOY ${ }^{2}$ \\ ${ }^{1}$ Atatürk Bahçe Kültürleri Merkez Araştırma Enstitüsü, Gıda Teknolojisi Bölümü, Yalova, Türkiye. \\ ${ }^{2}$ Ege Üniversitesi Ziraat Fakültesi, Bahçe Bitkileri Bölümü, İzmir, Türkiye.
}

Öz

Kiraz (Prunus avium L.) Türkiye'nin önemli ihraç ürünlerinden olup, aynı zamanda çabuk bozulabilir meyve türüdür. Daha çok taze olarak sofralık tüketilen kiraz meyvesinin muhafaza süresini arttırmak ve kalite özelliklerini devam ettirmesi için farklı muhafaza yöntemleri uygulanmaktadır.Bu yöntemlerden biride antimikrobiyal özelliklerinden de faydalanılabilecek olan uçucu yağlardır. Bu araştırma ile Türkiye'de yaygın olarak yetiştirilen ve ihracatı yapılan kiraz çeşitleri olan 0900 Ziraat, Regina ve Sweetheart kiraz çeşitlerinin depolama süresince fenolik bileşiklerin değişimi incelenmiştir. Bu çalışmada Türkiye'de yaygın olarak yetiştirilen kekik ve adaçayının uçucu yağlarından olan karvakrol ve thujon kullanılmıştır. Bunlar gazlı beze emdirilerek ortama konulmuş ve sodyum bikarbonat (\%2) çözeltisine daldırılarak MAP (modifiye atmosfer paket)’te soğukta muhafaza edilerek 8 hafta süreyle depolanmıştır.

Depolama süresi boyunca 15 günde bir olmak üzere kirazda bulunan önemli fenolik bileşiklerden olan klorojenik asit ve epikateşin miktarları belirlenmiştir. 8 hafta depolama süresince bu bileşiklerdeki değişimler değerlendirilmiştir. Klorojenik asit ve epikateşin fenolik bileşiklerin miktarı, 8 hafta depolama süresi boyunca tüm çeşitlerde yükseldiği belirlenmiştir. Klorojenik asit 0900 Ziraat çeşidinde 30,30-65,60 mg/100g, Sweetheart çeşidi kirazlarda 33,27-58,30 mg/100g, Regina Çeşidinde ise 53,50-112,43 mg/100g. olarak belirlenmiştir. Epikateşin miktarı ise; 0900 Ziraat çeşidinde 6,70-9,87 mg/100g, Sweatheart çeşidinde 6,60-10,50mg/100g, Regina çeşidinde 6,87-10,97 mg/100g arasında tespit edilmiştir.

Anahtar Kelimeler: Fenolik bileşenler, hasat sonrası muhafaza, kiraz, uçucu yağ,.

\section{Effects of Pre-treatments Some Sweet Cherry Cultivars On Epicatechin and Chlorogenic Acid Content During The Storage}

\begin{abstract}
Sweet cherry (Prunus avium L.) is one of Turkey's major export products, but also the perishable fruit species. Different preservation methods are applied to sweet cherry fruit, which is more likely to be consumed as fresh fruit, in order to increase conversation time and maintain the quality characteristics. One of the these methods are coating with essentail oils which also utilized antimicrobial properties. In this research, 0900 Ziraat, Regina and Sweetheart cherry varieties are widely grown in Turkey and exports change of phenolic compounds were investigated during storage. In this study, one of the widely grown thyme and sage essential oils (carvacrol and thujone) were used, carvacrol and thujone. It was placed in a gauze impregnated media and sodium bicarbonate (2\%) was immersed MAP (modified atmosphere packaging) te be kept cold were stored for 8 weeks

Storage time during the amounts of chlorogenic acid and epicatechin is one of the major phenolic compounds were determined every 15 days. The variance of these compounds were evaluated for 8 weeks storage. During the 8 weeks of storage epicatechin and chlorogenic acid were determined to be increased in all varieties. Chlorogenic acid was determined from 30.30 to $65.60 \mathrm{mg} / 100 \mathrm{~g}$ for 0900 Ziraat, from 33.27 to $58.30 \mathrm{mg} / 100 \mathrm{~g}$ for Sweetheart, while from 53.50 to $112.43 \mathrm{mg} / 100 \mathrm{~g}$ for Regina variety. Epicatechin was determined 0900 Ziraat variety 6.70 to $9.87 \mathrm{mg} / 100 \mathrm{~g}$ in the kinds Sweatheart 6,60-10,50mg / 100g, Regina cultivar 6,87-10-97 mg / 100g in was determined.
\end{abstract}

Keywords: Sweet Cherry, essential oils, phenolic compounds, post-harvest preservation.

*e-mail: zekiyegoksel@gmail.com 
Göksel Z., Aksoy U.

\section{Giriş}

Meyveler fenolik bileşenleri içermesiyle doğal bir antioksidan kaynağı kabul edilir. Bu bileşenler oksidatif stresin neden olduğu kardivasküler hastalıklar ve kanser riskini azaltabilir. Kırmızı meyveler grubunda olan kiraz bu bileşikler bakımından zengindir. Kiraz meyvesinin fenolik bileşenleri içerdiği rapor edilmiştir. Fenolik bileşiklerin miktarı meyvenin çeşidine ve iklim koşullarına göre değişim göstermektedir [1-3].

Kiraz, son yıllarda ihracatında yaşanan olumlu gelişmeler nedeni ile üretimi hızla artış gösteren bir meyve türü olmuştur. Kiraz, önemli ticari değeri olan bir ürün olması nedeniyle taze sofralık olarak tüketilecek meyvenin de yüksek kaliteli olması gerekmektedir. Sap rengi, önemli bir kalite unsurudur ve kahverengi saplar çoğunlukla tüketiciler tarafından kirazların reddiyle sonuçlanmaktadır. Kirazların belli dönemlerde olgunlaşması ve çabuk bozulabilir bir yapıya sahip olmaları nedeniyle kısa sürede pazarlaması gerekir. Tüketim süresini uzatmak ve mevsim dışı pazarlanabilmesi açısından değişik yöntemlerle muhafaza edilebilmeleri büyük önem taşımaktadır. Bu nedenle kirazların depolanmasında uçucu yağların etkisinden faydalanılmaya çalışılmıştır.

Fenolik bileşikler bitkilerde fazla miktarda bulunan sekonder metabolitlerdir. Bitkilerin ikincil metabolizma ürünleri olarak tanımlanan fenolik bileşikler bitkilerde en yaygın bulunan maddeler grubu olup, günümüzde binlerce fenolik bileşiğin yapısı tanımlanmıştır. Bitkilerde bulunan fenolik bileşikler fenolik asitler ve flavonoidler olarak iki gruba ayrılırlar. Yapısal olarak büyük farklılıklarından dolayı bitkilerde ve bunlardan elde edilen ürünlerde binlerce farklı fenolik bileşik bulunmaktadır. Fenolik bileşikler bitki kökenli pek çok gıdanın tat ve aromasına katkıda bulunabilirler. Özellikle gıdalarda acılık ve burukluğun kaynağıdırlar. Fenolik bileşikler doğal antioksidan madde özelliği de göstermektedirler. Serbest radikallerin neden olduğu reaksiyonları durdurarak veya engelleyerek kanser, kalp hastalığı ve akciğer hastalıkları gibi pek çok hastalıkların oluşumuna engel olurlar.

Fenolik bileşikler, gıda maddelerinin görünüş, tat ve lezzet gibi tüketim açısından önemli olan kalite özellikleri üzerine etkileri ve doğal antioksidan olarak insan sağlığı üzerine olumlu etkileri nedeniyle önemli bileşenlerdir. Fenolik bileşikler gıdaların acılık ve burukluk gibi lezzet unsurları üzerine etki ettiğinden dolayı, özelliklede meyve sebzeler ve bunlardan elde edilen ürünler için çok önemli bileşiklerdir. Meyve sebzelerde niteliklerine göre çeşitli fenolik bileşikler farklı oranlarda bulunabilmekte ve gıdaların renk, tat ve lezzetini etkileyerek gıdaların albenisini önemli şekilde etkilemektedirler. Ayrıca fenolik bileşiklerin doğal antioksidan kaynağı olmaları ve dolayısı ile sağlık üzerine olumlu etkileri nedeniyle meyve ve sebze ürünlerine olan ilgi gün geçtikçe artmaktadır [4].

Son zamanlarda meyve ve sebzelerin fenolik bileşenlerin sağlık açısından değerlendirildiği çalışmalar artmıştır. Bu bileşikler arasında araştırmalar antioksidan aktivite göstermeleri açısından antosiyaninler ve polifenoller üzerine yoğunlaşmaktadır. Kiraz çeşitleri duyusal, beslenme ile ilgili ve biyoaktif bileşenler açısından farklılıklar göstermektedir. Depolandıktan sonra yapılan analizlerde fenolik maddelerde ortalama \%40-60 oranında artış olduğu görülmüştür. Kiraz çeşitlerinde hidrosinnamik asitlerin ana bileşeni olarak neochlorogenik asit bulunmuştur. Fenolik bileşiklerin rengi dolayısı ile meyve kalitesini etkilemesinin yanı sıra tat, koku ve lezzetin daha yüksek fenolik içeriğiyle ilişkili olacağ bildirilmiştir [5 ve 2]. Meyve sebzelerde niteliklerine göre çeşitli fenolik bileşikler farklı oranlarda bulunabilmekte ve gıdaların renk, tat ve lezzetini etkileyerek gıdaların albenisini önemli şekilde 
etkilemektedirler. Ayrıca fenolik bileşiklerin doğal antioksidan kaynağı olmaları ve dolayısı ile sağlık üzerine olumlu etkileri nedeniyle meyve ve sebze ürünlerine olan ilgi gün geçtikçe artmaktadır [4]. Ayrıca Kirazın bazı ön işlemlerle depolanmasının fenolik bileşenler üzerinde çeşide ve koşullara bağlı olarak değişim gösterdiği bildirilmiştir [6-9].

\section{Materyal ve Metot}

\subsection{Materyal}

Araştırmanın materyalini Yalova Atatürk Bahçe Kültürleri Merkez Araştırma Enstitüsü Bahçesinden hasat edilen 0900 Ziraat, Sweetheart ve Regina olmak üzere üç kiraz çeşidi oluşturmuştur. Ayrıca denemede, ön işlemlerde kekik uçucu yağ etken maddesi karvakrol, adaçayı uçucu yağı etken maddesi thujon ve sodyum bikarbonat kullanılmıştır. Pasif modifiye atmosfer paketleme için halen kiraz ihracatında kullanılan Xtend, 2 kg'lık ticari poşetler Stepac firmasından temin edilerek kullanılmıştır.

Kirazlar renk, boy ve yeşil sap rengi bakımından homojen bir şekilde hasat edilerek diğer işlemler için enstitü laboratuvarına getirilmiştir. Her uygulama için 8 paket ve bir kontrol olmak üzere 2 şer kg tartılarak uygulamaya alınmıştır.

\section{2. $\quad$ Metot}

Modifiye atmosfer paketleme şeklinde depolanacak kirazlar Xtend paketlerin içine konulmuştur. Doğal bileşenler olan uçucu yağ ana bileşenleri karvakrol ve thujon 0900 Ziraat, Regina ve Sweetheart çeşitleri için $200 \mu 1$ steril gazlı beze emdirilerek paketlerin içine konulmuştur.

Hasat sonrası kirazlar oda sıcaklığındaki \%2'lik sodyum bikarbonat $\left(\mathrm{NaHCO}_{3}\right)+\% 0.5$ sitrik asit içeren çözeltiye 2 dakika daldırılmıştır. Bu uygulama sonunda kirazlar süzülerek oda sıcaklığında 10 dakika kurumaya bırakılmıştır. Kuruyan kirazlar 2 kg'lık MAP'de muhafaza edilmek üzere Xtend torbalara konularak ağzı kapatılmıştır. Etkileri takip edilmek üzere sonra $1,5 \pm 0,5^{\circ} \mathrm{C}$ sıcaklık ve $\% 85-90$ oransal nemde depolanmıştır.

\section{Fenolik bileșenlerin HPLC'de analizi}

(-)-epikateşin, klorojenik asit bileşenleri analiz edilmiştir.

HPLC de yapılacak analiz için örneklerin ekstraksiyonu: Kiraz meyvesi örnekleri çekirdeklerinden ayrılarak blender da 2dk. püre haline getirildi. 4g püre haline gelmiş kiraz örneklerine $40 \mathrm{ml}$. sulu metanol (\% 70) eklendi. $20 \mathrm{dk}$. çalkalayıcıda çalkalanarak, 30dk. 15000rpm. santrfüj edildi. Süpernatantlar alınarak, $40{ }^{\circ} \mathrm{C}$ de rotary evaparatörde vakum altında kurutma işlemi yapıldı. Kurutulan örnekler $10 \mathrm{ml}$. \% 70 lik sulu metanolde çözündürülerek, analiz edilinceye kadar $-20{ }^{\circ} \mathrm{C}$ de muhafaza edildi [10 ve 11].

\section{HPLC çalışma şartları;}

DAD dedektör

$280 \mathrm{~nm}$

$\mathrm{C}_{18}(150 \times 4.6 \mathrm{~mm} 3 \mu \mathrm{m}$; Phenomenex $) 25^{\circ} \mathrm{C}$

$0.01 \mathrm{M}$ fosforik asit (A) ve $100 \%$ metanol (B) linear gradient

Enjeksiyon miktarı $10 \mu \mathrm{l}$ ve akış hızı $1 \mathrm{ml} / \mathrm{dk}$ [12]. 
Göksel Z., Aksoy U.

\section{Verilerin Analizi}

Çalışmada depolama süresi ana parsel faktör, uygulama (karvakrol, thujon, sodyum bikarbonat) alt parsel faktörü olmak üzere 3 tekrarlı Tesadüf Parselleri Bölünmüş Parseller deneme deseni kullanılmıştır. Çeşitlerin her biri kendi içerisinde değerlendirilmiştir. İstatistiksel analizlerde JMP (The Statistical Discovery Software) paket programından yararlanılmıştır [13]. Ortalamalar arasındaki farklılıkların saptanmasında LSD (LS Means Differences Student’s t ) testi $\mathrm{P}<0,05$ Lest Significant önem düzeyinde kullanılmıştır. Çizelgeler- Differences $\mathrm{P}<0,05$ 'da “Depolama Süresi x Uygulama” interaksiyonuna ait LSD gruplandırılmalarında küçük harfler kullanılmıştır [14].

\section{Bulgular}

Kiraz çeşitlerinin depolama süresince 0900 Ziraat, Regina ve Sweetheart çeşitlerinin epikateşin ve klorojenik asit miktarındaki değişimler tablo 1 , tablo 2 ve tablo 3 'te verilmiştir. her kiraz çeşidi kendi içinde değerlendirilmiştir.

Uygulamalar sonucunda 8 haftalık depolama süresince iki haftada bir olmak üzere analiz yapılarak klorojenik asit ve epikateşin miktarındaki değişimler incelenmiştir. depolama yapılmadan önce ilk yapılan analizde klorojenik asit miktarı en yüksek $81,50 \mathrm{mg} / 100 \mathrm{~g}$ ile regina çeşidinde tespit edilirken bunu 41,60mg/100g ile sweatheart ve 31,18 mg/100ile 0900 ziraat kiraz çeşidi takip etmiştir. epikateşin miktarı ise en yüksek yine regina çeşidinde $9,87 \mathrm{mg} / 100 \mathrm{~g}$ daha sonra sırasıyla sweatheart çeşidinde $8.00 \mathrm{mg} / 100 \mathrm{~g}$ ve 0900ziraat kiraz çeşidinde $7,90 \mathrm{mg} / 100 \mathrm{~g}$ olarak belirlenmiştir. depolama süresince klorojenik asit; 0900 ziraat çeşidinde 30,30-65,60 mg/100g, sweetheart çeşidi kirazlarda 33,27-58,30 $\mathrm{mg} / 100 \mathrm{~g}$, regina çeşidinde ise 53,50-112,43 mg/100g değerleri arasında olduğu belirlenmiştir. epikateşin miktarına baktığımızda çeşitlerin belirlenen miktarı; 0900 ziraat çeşidinde 6,70-9,87 mg/100g, sweatheart çeşidinde 6,60-10,50mg/100g, regina çeşidinde 6,87-10,97 mg/100g arasında tespit edilmiştir. klorojenik asit miktarı, 8 hafta depolama süresi boyunca tüm çeşitlerde yükseldiği belirlenmiştir. kontrole göre yapılan uygulamalardan en iyi sonuç veren uygulamanın 0900 ziraat kiraz çeşidinde karvakrol, regina ve sweatheart çeşidi kirazlarda thujon uygulamasının daha iyi sonuç verdiği belirlenmiştir. epikateşin miktarının depolama süresi boyunca bazı haftalarda azalma eğiliminde olsa da depolamanın son haftalarında yükselme belirlenmiştir.

Tablo 1. Muhafaza süresince 0900 Ziraat kiraz çeşidinin Klorojenik Asit ve Epikateşin miktarında (mg/100g) meydana gelen

\begin{tabular}{|c|c|c|c|c|c|c|c|c|}
\hline \multicolumn{5}{|c|}{ Klorojenik Asit } & \multicolumn{4}{|c|}{ Epikateşin } \\
\hline & Kontrol & Karvakrol & Thujon & $\begin{array}{l}\text { Sodyum } \\
\text { Bikarbonat }\end{array}$ & Kontrol & Karvakrol & Thujon & $\begin{array}{l}\text { Sodyum } \\
\text { Bikarbonat }\end{array}$ \\
\hline 0.gün & $31,17 \mathrm{~g}$ & $31,17 \mathrm{~g}$ & $31,17 \mathrm{~g}$ & 31,17 g & 7,90 b-d & 7,90 b-d & 7,90 b-d & 7,90 b-d \\
\hline 2.hafta & $30,30 \mathrm{~g}$ & $31,07 \mathrm{~g}$ & $49,70 \mathrm{~d}$ & $43,50 \mathrm{e}$ & 7,47 c-g & $6,90 \mathrm{fg}$ & $6,70 \mathrm{~g}$ & 7,00 e-g \\
\hline 4.hafta & $30,40 \mathrm{~g}$ & 55,30 bc & $39,80 \mathrm{f}$ & $40,10 \mathrm{f}$ & 7,80 b-e & $6,77 \mathrm{~g}$ & 7,80 b-e & $7,07 \mathrm{e}-\mathrm{g}$ \\
\hline 6.hafta & $57,97 \mathrm{~b}$ & $54,10 \mathrm{c}$ & $54,10 \mathrm{c}$ & $38,50 \mathrm{f}$ & $7,70 \mathrm{~b}-\mathrm{f}$ & $8,30 \mathrm{~b}$ & 7,37 d-g & 7,90 bd \\
\hline 8.hafta & 65,06 a & $57,77 \mathrm{~b}$ & $65,60 \mathrm{a}$ & $65,50 \mathrm{a}$ & 8,27 bc & 9,87 a & 8,07 b-d & 8,27 bc \\
\hline
\end{tabular}

Tablo 2. Muhafaza süresince Regina kiraz çeşidinin Klorojenik Asit ve Epikateşin miktarında (mg/100g) meydana gelen değişimler.

\begin{tabular}{|c|c|c|c|c|c|c|c|c|}
\hline \multicolumn{5}{|c|}{ Klorojenik Asit } & \multicolumn{4}{|c|}{ Epikateşin } \\
\hline & Kontrol & Karvakrol & Thujon & $\begin{array}{c}\text { Sodyum } \\
\text { Bikarbonat }\end{array}$ & Kontrol & Karvakrol & Thujon & $\begin{array}{c}\text { Sodyum } \\
\text { Bikarbonat }\end{array}$ \\
\hline 0.gün & $81,50 \mathrm{f}$ & $81,50 \mathrm{f}$ & $81,50 \mathrm{f}$ & $81,50 \mathrm{f}$ & $9,87 \mathrm{~cd}$ & $9,87 \mathrm{~cd}$ & $9,87 \mathrm{~cd}$ & $9,87 \mathrm{~cd}$ \\
\hline 2.hafta & $64,17 \mathrm{~g}$ & $70,77 \mathrm{~g}$ & $53,50 \mathrm{~h}$ & 96,50 c-e & 10,30 bc & $8,17 \mathrm{fg}$ & $6,40 \mathrm{~h}$ & $9,57 \mathrm{~cd}$ \\
\hline 4.hafta & $104,00 \mathrm{bc}$ & $97,70 \mathrm{~cd}$ & $86,80 \mathrm{f}$ & $84,50 \mathrm{f}$ & $11,60 \mathrm{a}$ & 9,50 de & $6,63 \mathrm{~h}$ & $8,40 \mathrm{fg}$ \\
\hline 6.hafta & $64,17 \mathrm{~g}$ & $72,30 \mathrm{~g}$ & $54,50 \mathrm{~h}$ & $89,57 \mathrm{~d}-\mathrm{f}$ & $6,87 \mathrm{~h}$ & 9,50 de & $6,70 \mathrm{~h}$ & $7,67 \mathrm{~g}$ \\
\hline 8.hafta & 89,27 ef & $112,43 \mathrm{a}$ & $84,07 \mathrm{f}$ & $108,00 \mathrm{ab}$ & 8,80 ef & $9,97 \mathrm{~cd}$ & $6,27 \mathrm{~h}$ & $10,97 \mathrm{ab}$ \\
\hline
\end{tabular}


Nevşehir Bilim ve Teknoloji Dergisi Cilt 6(ICAFOF 2017 Özel Sayı) 207-214 2017

Tablo 3. Muhafaza süresince Sweetheart kiraz çeşidinin Klorojenik Asit ve Epikateşin miktarında (mg/100g) meydana gelen değişimler.

\begin{tabular}{ccccccccc}
\hline & \multicolumn{3}{c}{ Klorojenik Asit } & \multicolumn{2}{c}{ Epikateşin } \\
& Kontrol & Karvakrol & Thujon & $\begin{array}{c}\text { Sodyum } \\
\text { Bikarbonat }\end{array}$ & Kontrol & Karvakrol & Thujon & Sodyum \\
0.günarbonat & & & $8,00 \mathrm{e}$ & $8,00 \mathrm{e}$ & $8,00 \mathrm{e}$ & $8,00 \mathrm{e}$ \\
2.hafta & $41,60 \mathrm{~d}$ & $41,60 \mathrm{~d}$ & $41,60 \mathrm{~d}$ & $41,60 \mathrm{~d}$ & $6,60 \mathrm{~h}$ & $8,90 \mathrm{~d}$ & $7,30 \mathrm{fg}$ & $7,00 \mathrm{~g}$ \\
4.hafta & $33,27 \mathrm{fg}$ & $26,97 \mathrm{~h}$ & $34,80 \mathrm{f}$ & $33,87 \mathrm{fg}$ & $7,47 \mathrm{f}$ & $9,67 \mathrm{bc}$ & $8,97 \mathrm{~d}$ & $9,00 \mathrm{~d}$ \\
6.hafta & $44,00 \mathrm{~cd}$ & $34,50 \mathrm{f}$ & $37,10 \mathrm{ef}$ & $29,90 \mathrm{gh}$ & $9,70 \mathrm{~b}$ & $8,27 \mathrm{e}$ & $9,57 \mathrm{bc}$ & $8,17 \mathrm{e}$ \\
8.hafta & $53,27 \mathrm{~b}$ & $58,30 \mathrm{a}$ & $43,47 \mathrm{~cd}$ & $57,47 \mathrm{a}$ & $9,37 \mathrm{c}$ & $10,50 \mathrm{a}$ & $9,67 \mathrm{bc}$ & $9,67 \mathrm{bc}$ \\
\hline
\end{tabular}

\section{Tartışma ve Sonuç}

Meyve ve sebzelerde özellikle hidroksinamik asidin esterleri çok yaygındır. o-kuinik asidin kafeik asit esteri olan klorojenik asit meyvelerde yaygın hatta tek baskın fenolik bileşik olabilen önemli bir hidrosinamik asit türevi bileşiktir [15]. Kateşinler ise bitkiler aleminde en yaygın halde bulunan flavonoidlerdir. Renksizdirler ve çoğunlukla serbest halde bulunurlar. Kateşinler kimyasal yapıları açısından flavan 3-ol'lerdir [16]. En sık bulunanları, (+)-kateşin, (-) epikateşin, (+)-gallokateşin, (-)epigallokateşindir [16 ve 17]. Vişne (Prunus cerasus) ve tatlı kiraz (Prunus avium)'da ortak olan bileşiklerden biri de baskın flavanol olan (-)-epikateşindir [18]. Birçok meyve serbest formda monomerik flavan-3-ol içerir ve bu içerik, tür ve çeşide göre oldukça önemli fakl1lıklar göstermektedir. Meyvelerdeki flavan-3-ol miktarı, kırmızı frenk üzümleri için $0.50 \mathrm{mg} / 100 \mathrm{~g}$ 'dan, taze kayısılar için $24.60 \mathrm{mg} / 100 \mathrm{~g}$ 'a kadar değişmektedir. Kateşin ve epikateşin meyvelerdeki hakim flavan-3-ollerdir [17 ve 19]. Daha önce rapor edildiğine göre kateşin türevi((-) epikateşin gallat) güçlü biyolojik aktivite, hücre ölümlerini engellemesi ya da durdurması olmak üzere güçlü bir etki gösterdiği bildirilmiştir. Ayrıca yeşil çayda bulunan epigallokateşin gibi çeşitli kateşin türevleri ile epikateşin-3-gallat ve epikateşin bileşenlerinin kanseri önleyici etkileri olduğu bildirilmiştir. [20 ve 21] yaptıkları çalışmada epikateşin ve diğer kateşin türevlerinin tümörün gelişimini engellediğini bildirmişlerdir.

Klorojenik asit, miktarca en fazla bulunan sinamik asit türevidir. Yaş ağırlığa göre elma ve kirazlarda 130-140 mg/g klorojenik asit bulunur [22]. [23], yaptıkları çalışmada Hırvatistan'da yetişen kiraz çeşitlerinde fenolik asitlerin dağılımı incelenmiş̧ir. Farklı kiraz çeşitlerinde klorojenik asit miktarı $19-62 \mathrm{mg} / \mathrm{kg}$ olarak bulunmuştur. Toplam fenolik asitler içerisinde klorojenik asit miktarının \%26-48 arasında en yüksek olduğu belirlenmiştir. Bizimde yaptığımız çalışmada üç çeşit kiraz çeşidinde de klorojenik asit miktarının epikateşinden daha yüksek miktarda olduğu belirlenmiştir. Yapılan çalışmalarda kiraz çeşitleri içerisinde klorojenik asidin en baskın hidrosinamik asit olduğunu belirtmişler ve aynı zamanda fenolik bileşiklerin konsantrasyonlarının olgunlaşma sürecinin ilerlemesiyle birlikte soğuk depolama süresince \%40-60 oranında yükseldiği görülmüştür [ 8-24-25-26-27-12]. Bu çalışmada da depolama sonucunda genel olarak fenolik bileşenlerin miktarının arttığı görülmüştür.

Hasat sonrasında depolama fitokimyasalların konsantrasyonlarını etkileyebilir. Yapılan çalışmalarda genel olarak hasat sonrasında fenolik bileşenlerin \%40-\%60 oranında bir artış gözlenmiştir [6-1]. Depolama sırasındaki değişim oranı fenolikten fenoliğe oldukça farklıdır. Bileşenlerin değişimi \% olarak ifade edilmiştir. [8] , kirazda uygulama yapılmamış ve hasat sonrası uygulama yapılmış olan kirazların soğukta muhafazasında klorojenik asit miktarlarında istatiksel olarak çok farklılık olmadığı ve \%72-\%76 oranında olduğu belirlenmiştir. Fenoliklerin depolama sırasındaki azalması hem kondensasyonla hem de degradasyonla ilişkili olabilir [28]. Depolama sırasında klorojenik asit daha stabildir. Epikateşin Depolamada \% 50’ye varan kayıplar tespit edilmiş̧ir. 
Yapılan çalışmada [29], kirazda bulunan temel fenolik bileşiklerden olan klorojenik asit miktarının armut meyvelerinde $0.12 \mathrm{mg} / \mathrm{g}$ olarak tespit edilmiştir. Yapmış olduğumuz çalışmada, kiraz meyve etindeki klorojenik asit miktarının 31.17-81.50 mg/100g olarak tespit edilmiştir. Klorojenik asit, enzimatik kahverengileşmesinde rol alan temel o-difenollerden olması ile yapılan bazı çalışmalarda miktarının meyve gelişimi ve olgunlaşması sırasında arttığı ve daha sonraki evrelerde özellikle muhafaza aşamasında azalma eğilimi gösterdiği tespit edilmiştir [30]. Yaptığımız çalışmada klorojenik asit miktarlarında görülen değişimler istatistiki olarak önemli bulunmuş, muhafaza başlangıcında meyvede tespit edilen klorojenik asit miktarının, muhafaza süreci boyunca bazı haftalarda azalış gösterse de muhafaza süresi sonunda arttığı görülmüştür (Tablo 1, 2,3). Çalışmamızda klorojenik asit miktarlarının muhafaza süresince artmış olması, kahverengileşme reaksiyonlarında önemli rolü olduğu bilinen klorojenik asit oksidasyonundan kaynaklanabileceği düşünülmektedir.

Depolama süresi boyunca fenolik bileşenlerin değişiminde yapılan uygulamaların etkisi istatistiki olarak önemli bulunmuştur. 0900 Ziraat çeşidinde klorojenik asit miktarında en az artış karvakrol uygulamasında görülürken diğer uygulamaların hepsi aynı grupta yer almıştır. Kateşin miktarında ise en fazla artış karvakrol uygulamasında tespit edilirken, sodyum bikarbonat ve kontrol aynı grupta yer alarak daha sonra thujon uygulaması takip etmiştir. Regina çeşidinde ise klorojenik asit miktarı depolama süresi sonunda en fazla karvakrol uygulamasında yükselirken en az yükselme thujon uygulamasında görülmüştür. Epikateşin miktarında ise en az değişiklik olan uygulama karvakrol olmuştur. Sweetheart kiraz çeşidinde ise klorojenik asit miktarı en az thujon uygulamasında olurken bunu kontrol, sodyum bikarbonat ve karvakrol takip etmiştir. Epikateşin miktarında kontrol grubunda en az artışın olduğu belirlenmiştir. Fenolik bileşenlerin miktarının muhafaza süresince değişimi; hasattaki olgunluk, çeşit, büyüme sezonu, depolama süresi gibi birçok faktöre bağlı olduğu bildirilmiştir [6-7-1]. Kiraz meyvesinin sahip olduğu fenolik bileşik içeriğiyle özellikle de klorojenik asit miktarı göz önüne alındığında kendisinin sağlık açısından değerli bir meyve olarak kabul edilebileceği sonucuna varılmıştır.

\section{Kaynaklar}

[1] Serrano, M., Martínez-Romero, D., Castillo, S., Guill_en, F.,Valero, D., “The use of natural compounds improves the beneficial effect of MAP in sweet cherry storage”. Innovative Food Science Emerging Technology, 6, 115-123,2005

[2] Papp, N.,Szilvássy, B.,Abrankó, L.,"Main quality attributes and antioxidants in Hungarian sour cherries: identification of genotypes with enhanced functional properties”, International Journal of Food Science and Technology, 45, 395-402, 2010.

[3] Prvulović D., Malenčić D., Popović M., Ljubojević M., ve Ognjanov V., “Antioxidant Properties of Sweet Cherries (Prunus avium L.) - Role of Phenolic Compounds”, World Academy of Science, Engineering and Technology 5,11-25. 2011

[4] Nizamlığlu N.M., Sebahattin N., "Meyve ve sebzelerde bulunan fenolik bileşikler; yapıları ve önemleri”, Electronic Journal of Food Technologies 5 (1) , 20-35, 2010

[5] Serrano, M.; Díaz-Mula, H.; Zapata, P. J.; Castillo, S.; Guill_en, F.; Martínez-Romero, D.; Valverde, J. M.; Valero, D., “ Maturity stage at harvest determines the fruit quality and antioxidant potential afterstorage of sweet cherry cultivars”, Journal of Agricaltural and Food Chemistry, 57, 3240-3246, 2009 
[6] Gonc`alves, B., Landbo, A. K., Knudse, D., Silva, A. P., Moutinho- Pereia, J., Rosa, E., Meyer, A. S. , "Effect of ripeness and postharvest storage on the phenolic profiles of cherries (Prunus Avium L.)”, Journal of. Agricaltural and Food Chemistry, 52, 523-530, 2004a

[7] Gonc`alves, B., Landbo, A. K., Let, M., Silva, A. P., Rosa, E., Meyer, A. S., "Storage affects the phenolic profiles and antioxidant activities of cherries (Prunus Avium L.) on human low-density lipoproteins”, Journal of the Science of Food and Agricultural, 84, 1013-1020, 2004b

[8] Mozetič, B., Simičič, M.; Trebše, P., "Anthocyanins and hidroxycinnamic acids of Lambert Compact cherries (Prunus Avium L.) after cold storage and 1-methylcyclopropene treatments”, Journal Food Chemistry, 97, 302-309, 2006

[9] Esti, M., Cinquanta, L., Sinesio, F., Moneta, E., Matteo, D. M. , "Physicochemical and sensory fruit characteristics of two sweet cherry cultivars after cool storage”. Food Chemistry. 76, 399405, 2002

[10] Bakkalbası E., Yemiş O., Aslanova D. ve Artık N., "Major Flavan-3-ol Composition and Antioxidant Activity of Seeds From Different Grape Cultivars Grown in Turkey”, European Food Research and Technology, 221:792-797, 2005

[11] Yilmaz, Y. ve Toledo, R.T., "Major flavonoids in grape seeds and skins: Antioxidant capacity of catechin, epicatechin, and gallic acid”. Journal of Agricultural and Food Chemistry, 52 (2):25,2004

[12] Usenik, V. , Fabčič, J. and Štampar, F., "Sugars, organic acids, phenolic composition and antioxidant activity of sweet cherry (Prunus avium L.)”, Food Chemistry, 107(1), 185-192, 2008

[13] Acar, M. ve Gizlenci, Ş., “Tarımsal Araştırmacılar için JMP Kullanımı”. Karadeniz Tarımsal Araştırma Enstitüsü, Samsun, 2006

[14] Kalaycı, M., “Örneklerle Jump Kullanımı ve Tarımsal Araştırma İçin Varyans Analiz Modelleri”, Anadolu Tarımsal Araştırma Enstitüsü Müdürlüğü Yayınlarl, Yayın No: 21, Eskişehir, 2005

[15] Belitz H.-D. ve Grosch W. ,Food Chemistry, ISBN 978-3-662-07281-3 (eBook), 1999

[16] Cemeroğlu, B. , "Meyve ve Sebze İşleme Teknolojisi”, Gıda Teknolojisi Derneği Yayınları. Yayın no: 6, Ankara. 496 s., 2001

[17] Shahidi ve Naczk,. Food phenolics: Sources, Chemistry, Effects, Applications, Technomic Publishing Company Inc., Lancaster PA., pp: 231- 245, 1995

[18] Shahrzad S., Bitsch I. , "Determination of some pharmacologically active phenolic acids in juices by high-performance liquid chromatography”, Journal. Chromatography A.,741(2):22331, 1996

[19] Kyou-Nam, C., Mugdha, S., Seong-Ho, L., Joo-Heon, Y., “Green tea catechin, (-)epicatechin gallate induces tumor suppressor protein ATF3 via EGR-1 activation”, European Journal of Cancer,43, 2404-2412, 2007

[20] Gonza'lez-Go'mez, D. , Lozano, M. , Ferna'ndez-León, M. F. , Bernalte, M. J. , Ayuso, M. C. , Rodri'guez, A. B. , "Sweet cherry phytochemicals: Identification and characterization by HPLCDAD/ESI-MS in six sweet-cherry cultivars grown in Valle del Jerte (Spain)”, Journal of Food Composition and Analysis, 23(6), 533-539, 2010 
[21] Yang, C.S., Lambert, J.D., Ju, J., Lu, G., Sang, S., “ Tea and cancer prevention: molecular mechanism and human relevance”. Toxicology and Applied Pharmacology, 224, 265-273, 2007

[22] Karaçalı, İ. , "Bahçe Ürünlerinin Muhafaza ve Pazarlaması", Ege Üniversitesi Ziraat fakültesi Yayınları No: 494., 2006

[23] Jakobek, L., S`eruga, M. , Voc’a, S. , S`indrak, Z. , Dobric`evic, N. , "Flavonol and phenolic acid composition of sweet cherries (cv. Lapins) produced on six different vegetative rootstocks”, Scientia Horticultural 123, 23-28, 2009.

[24] Mozetič, B., Trebs`e, P., Hribar, J., "Determination and quantitation of anthocyanins and hydroxycinnamic acids in different cultivars of sweet cherries (Prunus avium L.) from Nova Gorica region (Slovenia)”, Journal Food Technol. Biotechnol, 40, 207-212, 2002

[25] Mozetic $`$, B., Trebs`e, P., “ Identification of sweet cherry anthocyanins and hydroxycinnamic acids using HPLC coupled with DAD and MS detector”. Acta Chimica. Slovenica, 51, 151158, 2004a

[26] Mozetič, B., Trebše, P., Simc`ic' , M., Hribar, J., " Changes of anthocyanins and hydroxycinnamic acids affecting the skin colour during maturation of sweet cherries (Prunus avium L.)”, Lebensm.-Wiss. Food Science and Technologyl. 37, 123-128, 2004

[27] Valero D., Díaz-Mula H. M., Zapata P. J., Castillo S., an Guillen F., Martínez-Romero D. and Serrano M., "Postharvest Treatments with Salicylic Acid, Acetylsalicylic Acid or Oxalic Acid Delayed Ripening and Enhanced Bioactive Compounds and Antioxidant Capacity in Sweet Cherry”, Journal of. Agricaltural and Food Chemistry., 59, 5483-5489, 2011

[28] Karadeniz, F. ve Ekşi, A. , "Elma suyunda esmerleşme düzeyi ile doğal etkenler arasındaki ilişki”, Tarım Bilimleri Dergisi, 7(4):102-105, 2001.

[29] Cu1, T., Nakamura K., Ma L., J. L1 ve Kayahara H., "Analyses of Arbutin and Chlorogenic Acid, the Major Phenolic Constituents in Oriental Pear”, Journal of. Agricaltural and Food Chemistry., 53:(10), pp 3882-3887, 2005

[30] Cemeroglu, B. ve Acar J., "Meyve ve Sebze İsleme Teknolojisi”, Gida Teknolojisi Derneği,Yayın No: 6. Ankara. 508 s., 1986 